\title{
Platelet inhibitors versus anticoagulants for prevention of aorto-coronary bypass graft occlusion
}

\author{
M. E. Rothlin*, N. Pfluger $†$, K. Speiser,+ N. Goebel $\$$, H.-P. Kra yenbühl $\uparrow$, W. Steinbrunn\|, \\ M. TURINA**, AND $\AA$. SENNING** \\ *Department of Medicine, University Hospital, $\mathrm{CH}-8091$ Zürich, $†$ Med. Klinik, Kantonsspital, \\ $\mathrm{CH}-6300$ Zug, ${ }_{+}$Med. Klinik, Kreisspital, CH-8620 Wetzikon, §Röntgeninstitut, Universitätsspital, \\ CH-809l Zürich, 9 Med. Poliklinik, Universitätsspital, $C H-8091$ Zürich, $\|$ Med. Klinik, \\ Universitätsspital, $\mathrm{CH}-8091$ Zürich and ${ }^{* *}$ Chirurgische Klinik A, Universitätsspital, $\mathrm{CH}-8091$ Zürich
}

KEYWORDS: Ticlopidine, acenocoumarol, platelet inhibitors, anticoagulants, coronary bypass patency rate.

The effects of the antiaggregant substance ticlopidine and of the anticoagulant acenocoumarol on patency rates of aorto-coronary bypass grafts were compared in a prospective randomized trial. Ticlopidine, $250 \mathrm{mg}$ b.i.d. was administered orally from the first postoperative day till angiography, while anticoagulation with acenocoumarol was initiated on the second to third postoperative day. Side-effects of ticlopidine were rare and patient management with the standard dosage of this drug was easier than oral anticoagulation. From an initial group of 166 randomized patients 149 completed the trial by coronary angiography three months postoperatively. The 78 patients in the ticlopidine group showed a compliance of $85 \%$. The average prothrombin time in the 71 patients receiving acenocoumarol was 26.9\%. Detailed statistical analysis of the two study groups revealed no reason to doubt the correctness of randomization.

Coronary angiography showed an average patency rate per patient of $84 \%$ with ticlopidine and of $82 \%$ with acenocoumarol. This and various other measures of graft occlusion did not reveal any substantial difference in graft patency of patients receiving ticlopidine or acenocoumarol. It is concluded that ticlopidine may well be used instead of anticoagulants for prevention of postoperative occlusion of aorto-coronary bypass grafts.

\section{Introduction}

Long standing patency of aorto-coronary bypass grafts is essential for good subjective and objective results of surgical myocardial revascularization $^{[1,2]}$. About $10 \%$ of bypass grafts become occluded within days of insertion and $16-26 \%$ during the first postoperative year ${ }^{[1-6]}$. Thrombosis plays an important role in early graft occlusion, while later obstruction is caused mainly by intimal proliferation and atherosclerosis ${ }^{[3-5]}$. For prevention of thrombosis, oral anticoagulants and platelet active drugs, namely aspirin, alone or in combination with dipyridamole as well as sulfinpyrazone have been tested in animal experiments $s^{[7.8]}$ and in clinical trials ${ }^{[6.9-17]}$.

Ticlopidine is a platelet inhibiting drug reducing

Received for publication on 16 November 1984

Address for reprints: Prof. M. E. Rothlin. Department of Medicine. Lniversity Hospital, $\mathrm{CH}-8091$ Zürich. Switzerland platelet aggregation and prolonging bleeding time; a potent antithrombotic activity has also been shown in animal models ${ }^{[18]}$. In mongrel dogs pretreatment with ticlopidine reduced adhesion and aggregation of platelets on arterial dacron grafts and significantly increased their patency rate up to 6 weeks after implantation ${ }^{[19]}$. In a randomized blinded clinical trial reported previously from this institution, ticlopidine or placebo were started 3 days before bypass surgery and were continued until angiography 3 months postoperatively; in addition all patients postoperatively received acenocoumarol as an oral anticoagulant ${ }^{[20]}$. When very severe bleeding occurred in a patient, this study had to be discontinued prematurely. It was found that ticlopidine significantly enhanced peri- and postoperative blood loss and led to a 6-fold increase of reoperation for bleeding. It was concluded, that preoperative administration of ticlopidine is not justified, 
Table I Criteria for exclusion of patients from the study.

1 Female sex

2 Previous bypass surgery

3 Additional surgical procedures such as left ventricular aneurysmectomy or valve replacement

4 Emergency operations

5 Diabetes requiring insulin or oral hypoglycaemics

6 Haematologic disorders

7 Liver or kidney disorder

8 Need for drugs influencing platelet function (acetylsalicylic acid, sulfinpyrazone, dipyridamole, non steroidantiinflammatory agents, clofibrate)

9 Patients, who did not give informed consent

although this study had revealed a significant reduction of perioperative infarction in patients receiving preoperative ticlopidine ${ }^{[21]}$. After 3 months, however, angiography did not show a significant increase in graft patency in patients treated pre- and postoperatively with ticlopidine. The reported significant reduction of graft occlusion by postoperative oral anticoagulation ${ }^{[10]}$ raises the question, whether anticoagulants, administered after surgery to all patients in our study, had concealed a positive effect of ticlopidine on graft occlusion. The present study was therefore designed to compare the effect of postoperative treatment with ticlopidine with oral anticoagulation by acenocoumarol with respect to thrombotic occlusion of aorto-coronary bypass grafts.

\section{Patients and methods}

\section{PATIENT RANDOMIZATION}

From February 1980 to August 1981, 407 patients had an aorto-coronary bypass operation at the University Hospital Zürich. Unless patients fulfilled any of the exclusion criteria listed in Table 1 , they were asked to participate in the study. A total of 166 patients consented and entered the trial. For randomization, 83 patients each were assigned to either ticlopidine or acenocoumarol by opening a consecutively numbered sealed envelope indicating the type of treatment. The envelopes were previously prepared by a statistician from the company providing ticlopidine according to a table of random numbers. All patients submitted to angiography 3 months postoperatively remained in their original treatment group for analysis of results, whether they adhered to their recommended treatment or not.

\section{MEDICATION AND MONITORING OF PATIENT COMPLIANCE}

Ticlopidine, $250 \mathrm{mg}$ b.i.d. was administered orally starting the first postoperative day until angiography was performed 3 months postoperatively. Each patient on ticlopidine treatment received a bottle with 200 tablets at hospital discharge, which was collected at the end of the study (postoperative coronary angiography) for a tablet count. Furthermore, platelet aggregation with collagen was tested preoperatively, before hospital discharge, 6 weeks after surgery and 3 months postoperatively to monitor compliance ${ }^{[22]}$.

Acenocoumarol was started after removal of the drainage tubes on the second or third postoperative day. Dosage was adjusted aiming at a prothrombin time of $20-25 \%$. The test was performed using a substrate prepared from human brain tissue. The prothrombin time determined 6 weeks postoperatively was used as a quality control of oral anticoagulation.

\section{ANGIOGRAPHY}

Three months after surgery, native vessels and bypass grafts were visualized by selective injections in orthogonal views. At the same time, ventricular cineangiography was performed in right and left anterior oblique projections; pressures were recorded before and after ventriculography. No serious complications occurred during postoperative angiographic studies. Angiograms were analysed without knowledge of the patient's group assignment by at least two observers. In case of vein grafts with two or more distal anastomoses, each segment was counted as one 'aorto-coronary bypass'. Implantation of the internal mammary artery into a coronary artery was also counted as one 'aorto-coronary bypass'. Patency was classified as occluded (grade 4), obstructed by more than $75 \%$ (grade 3 ), by $50-75 \%$ (grade 2 ) not severely stenosed including mild stenosis of less than $50 \%$ (grade 1).

An aorto-coronary bypass was called 'patent', if it was free of any grade 4 obstruction, and 'obstruction free', if no or only grade 2 stenosis was present. 
For statistical analysis of the patency rate in two treatment groups, individual bypass segments should not be used as observation units, because different bypass segments in an individual patient are not independent. Therefore we calculated for each patient a patency rate (PCY) defined as the ratio of patent segments to implanted segments. Moreover a rate of 'obstruction free' bypass grafts $\left(\mathrm{PCY}_{2}\right)$ was similarly calculated: 100 times the number of patent segments presenting with less than $75 \%$ stenosis divided by the number of implanted segments.

\section{STATISTICAL METHODS}

The base line data for the two groups were compared both by univariate methods ( $t$ test for continuous variables and chi squared test for categorical variables) and by a stepwise logistic regression with the treatment group as the dependent variable. The main comparison of the treatments was obtained from ordinary stepwise regression with the two target variables described above (PCY and $\mathrm{PCY}_{2}$ ) appearing in turn as dependent variables and base line characteristics as well as the type of medication as the independent variables. The medication variable assumed the value 0 for anticoagulation, and the value 1 for ticlopidine treatment. It was forced to enter the equation in order to obtain a confidence interval for its coefficient, which represents the treatment effect.

To get adequate results for the statistical tests, the patients had to be used as the observation units rather than the individual segments, since the patencies of the segments within the same patient showed a statistically significant correlation.

The calculations were done using BMCP programs at the computer center of Zürich University.

\section{Results}

PATIENT ADHERENCE, SIDE-EFFECTS AND COMPLIANCE

Out of 166 patients recruited for the trial, 5 receiving ticlopidine and 12 receiving anticoagulants, did not undergo angiography 3 months postoperatively; this corresponds to a drop out rate of $10 \%$. Reasons for not performing control angiography are listed in Table 2. Seventy-eight patients in the ticlopidine-group and 71 patients in the anticoagulant-group completed the study with postoperative coronary angiography. In addition to the complications possibly related to the type of treatment in Table 2, one patient receiving antico-
Table 2 Causes of not performing control angiography (drop out patients $-D . O$.) and side-effects requiring premature discontinuation of treatment in patients (C.S.), who completed the study

\begin{tabular}{|c|c|c|c|c|}
\hline & \multicolumn{2}{|c|}{$\begin{array}{l}\text { Anticoagulation } \\
\qquad(N=83)\end{array}$} & \multicolumn{2}{|c|}{$\begin{array}{c}\text { Ticlopidine } \\
(N=83)\end{array}$} \\
\hline & D.O. & C.S. & D.O. & C.S. \\
\hline Stroke & - & $1^{*}$ & - & - \\
\hline Haematuria & $1^{*}$ & - & - & - \\
\hline Intestinal haemorrhage & $1^{*}$ & - & - & - \\
\hline Myocardial infarction & $i$ & - & - & - \\
\hline Sudden death & 1 & - & - & - \\
\hline Pulmonary embolism & - & - & $2 \dagger$ & $2 \dagger$ \\
\hline Left heart failure & - & - & 1 & - \\
\hline Nausea and anorexia & - & - & $1^{*}$ & - \\
\hline $\begin{array}{l}\text { Refusal by patient or } \\
\text { private physician }\end{array}$ & 8 & - & 1 & - \\
\hline
\end{tabular}

*Direct side-effects

†Possible indirect side-effect, because patients did not receive anticoagulants

agulants experienced cerebral haemorrhage but was submitted to control angiography in spite of premature cessation of anticoagulants. In the ticlopidine-group, 4 patients discontinued medication prematurely: 2 because of severe gastrointestinal symptoms and 2 because ticlopidine was replaced by anticoagulants when the private physician suspected pulmonary embolism.

Patient compliance in the ticlopidine-group was $84 \%$ according to the tablet count and $86 \%$ when assessed by inhibited platelet aggregation. In patients receiving anticoagulants, prothrombin time determined 6 weeks postoperatively averaged $26.96 \pm 12 \cdot 30(\mathrm{SD}) \%$.

\section{COMPARISON OF THE TWO TREATMENT GROUPS}

Some selected preoperative characteristics of the two treatment groups are tabulated in Table 3. Table 4 illustrates operative characteristics of the two treatment groups. Comparison of base line data by univariate methods did not show any significant difference at the $5 \%$ level between the treatment groups. Moreover in a logistic stepwise regression run on 36 historical, clinical, angiographic and operative variables recorded before starting treatment, only 3 variables entered the regression equation with a $P$ value of less than $5 \%$ : perioperative infarction and a bypass to an intermediate branch of the left coronary artery were less frequent in the ticlopidine-group, anastomosis 
Table 3 Preoperative characteristics of the two treatment groups

\begin{tabular}{|c|c|c|}
\hline & $\begin{array}{l}\text { Anticoagulation } \\
\qquad(N=71)\end{array}$ & $\begin{array}{c}\text { Ticlopidine } \\
(N=78)\end{array}$ \\
\hline Age (years) & $53 \cdot 5 \pm 8 \cdot 2$ & $53 \cdot 2 \pm 6 \cdot 7$ \\
\hline $\begin{array}{l}\text { Duration of symptoms } \\
\text { (months) }\end{array}$ & $40-2 \pm 43 \cdot 6$ & $39 \cdot 3 \pm 42 \cdot 8$ \\
\hline $\begin{array}{l}\text { Previous myocardial } \\
\text { infarction }(\%)\end{array}$ & 62 & 59 \\
\hline $\begin{array}{l}\text { Average NYHA-class } \\
\text { Physical working capa- } \\
\text { city, }\end{array}$ & $2 \cdot 6 \pm 0.7$ & $2 \cdot 4 \pm 0.6$ \\
\hline $\begin{array}{l}\% \text { of predicted } \\
\text { Smoking, average pack }\end{array}$ & $62.9 \pm 24 \cdot 6$ & $62 \cdot 4 \pm 27 \cdot 3$ \\
\hline years & $22 \cdot 3 \pm 21 \cdot 3$ & $20 \cdot 2 \pm 17 \cdot 2$ \\
\hline Ejection fraction (\%) & $57 \cdot 3 \pm 10 \cdot 6$ & $59 \cdot 5 \pm 8 \cdot 9$ \\
\hline $\operatorname{LVEDP}(\mathrm{mmHg})$ & $13.8 \pm 6.7$ & $13 \cdot 6 \pm 5 \cdot 0$ \\
\hline Coronary score* & $7 \cdot 8 \pm 2 \cdot 6$ & $7 \cdot 4 \pm 2 \cdot 7$ \\
\hline $\begin{array}{l}\text { Number of main bran- } \\
\text { ches with obstructions }\end{array}$ & $2 \cdot 3 \pm 0 \cdot 8$ & $2.4 \pm 0.7$ \\
\hline
\end{tabular}

*Dash H, Johnson RA, Dinsmore RE, Harthorne JW, Cardiomyopathic syndrome due to coronary artery disease. $\mathrm{Br}$ Heart J 1977; 39: 733-9.

of a bypass to a postero-lateral branch of the right coronary artery was less common in the anticoagulant-group

ANGIOGRAPHIC PATENCY RATE OF AORTO-CORONARY BYPASS

Cineangiographic examination of patency of the aorto-coronary bypass did not reveal any substantial difference between the two treatment groups. Thirty out of 78 patients with ticlopidine and 30 out of 71 patients with anticoagulants had at least one occluded graft segment. Two patients out of 78 with ticlopidine and one patient out of 71 with anticoagulants had all grafts occluded. The average patency rate per patient (PCY) and the rate of 'obstruction free' bypass per patient $\left(\mathrm{PCY}_{2}\right)$ were very similar in both patient groups when compared in a histogram, as can be seen in Figs $I$ and 2.

A regression characterizing patients before medication including the location of the bypass segments, the size of the anastomosed coronaryartery, need for endarterectomy and type of bypass graft as possible risk factors for obstruction was performed for PCY and $\mathrm{PCY}_{2}$ (Table 5). Although a large number of possibly influential variables was examined, there was almost no influence of any of these on bypass patency with the exception of perioperative infarction and anastomosis to a third postero-lateral branch of the circumflex artery. The confidence intervals obtained for the true treatment effect (see statistical methods) range from $-7 \%$ to $+7 \%$ for PCY and from $-8 \%$ to $+10 \%$ for $\mathrm{PCY}_{2}$. This means that the two treatments had virtually identical effects on the patency of the grafts.

\section{Discussion}

The presented findings indicate, that the regimens of ticlopidine, an anti-platelet drug, and acenocoumarol, an oral anticoagulant, had virtually identical effects on aorto-coronary bypass graft patency studied 3 months after implantation.

The drop out rate of $10 \%$ in this trial compares favourably with that reported in previous trials testing platelet active drugs on patency of aortocoronary bypass grafts ${ }^{[6,10-16]}$. The lack of significant differences in univariate analysis of patient characteristics of the two treatment groups indicates proper randomization. Multivariate analysis showed only 3 variables, namely two uncommon localizations of graft anastomoses and perioperative infarction to enter the equation with a $P$ value of less than $5 \%$. Other risk factors for bypass occlusion including size of the grafted vessel, endarterectomy, use of $Y$-shaped grafts and single, double or multiple sequential grafts were not found to differ significantly in the two treatment groups. It was therefore concluded that there are no reasons to doubt the correctness of the randomization.

Patient compliance was satisfactory with about $15 \%$ of patients not taking ticlopidine regularly because of side-effects or insufficient cooperation. Prothrombin time determined 6 weeks postoperatively for testing the quality of anticoagulation with acenocoumarol averaged $26 \%$ and was somewhat higher than expected. Side-effects of ticlopidine were rare, only 3 patients discontinued the drug for nausea and anorexia. In the acenocoumarol group, there was cerebral haemorrhage, gastrointestinal haemorrhage and haematuria in one patient each. In no patient did permanent sequelae of the above mentioned side-effects occur.

An indirect effect of ticlopidine treatment as compared with oral anticoagulants may be seen in the occurrence of pulmonary embolism in two patients and suspicion of this complication in another two. Pulmonary embolism is recorded exceptionally in our experience with routine anticoagulation after aorto-coronary bypass 
Table 4 Operative characteristics of the two treatment groups

\begin{tabular}{|c|c|c|c|}
\hline & & $\begin{array}{l}\text { Anticoagulation } \\
\qquad(N=71)\end{array}$ & $\begin{array}{l}\text { Ticlopidine } \\
(N=78)\end{array}$ \\
\hline Aortic clamping time (min) & & $50 \cdot 9 \pm 19 \cdot 2$ & $51 \cdot 2 \pm 19 \cdot 6$ \\
\hline Grafts per patient & & $3 \cdot 2 \pm 1 \cdot 1$ & $3 \cdot 1 \pm 1 \cdot 0$ \\
\hline Number of segments per patient & $\begin{array}{l}1 \\
2 \\
3 \\
4 \\
5 \\
6\end{array}$ & $\begin{array}{r}6 \\
12 \\
23 \\
24 \\
4 \\
2\end{array}$ & $\begin{array}{r}3 \\
21 \\
26 \\
24 \\
4 \\
0\end{array}$ \\
\hline $\begin{array}{l}\text { Perioperative myocardial infarc- } \\
\text { tion }\end{array}$ & & 7 & 2 \\
\hline Rethoractomy for haemorrhage & & 3 & 3 \\
\hline
\end{tabular}

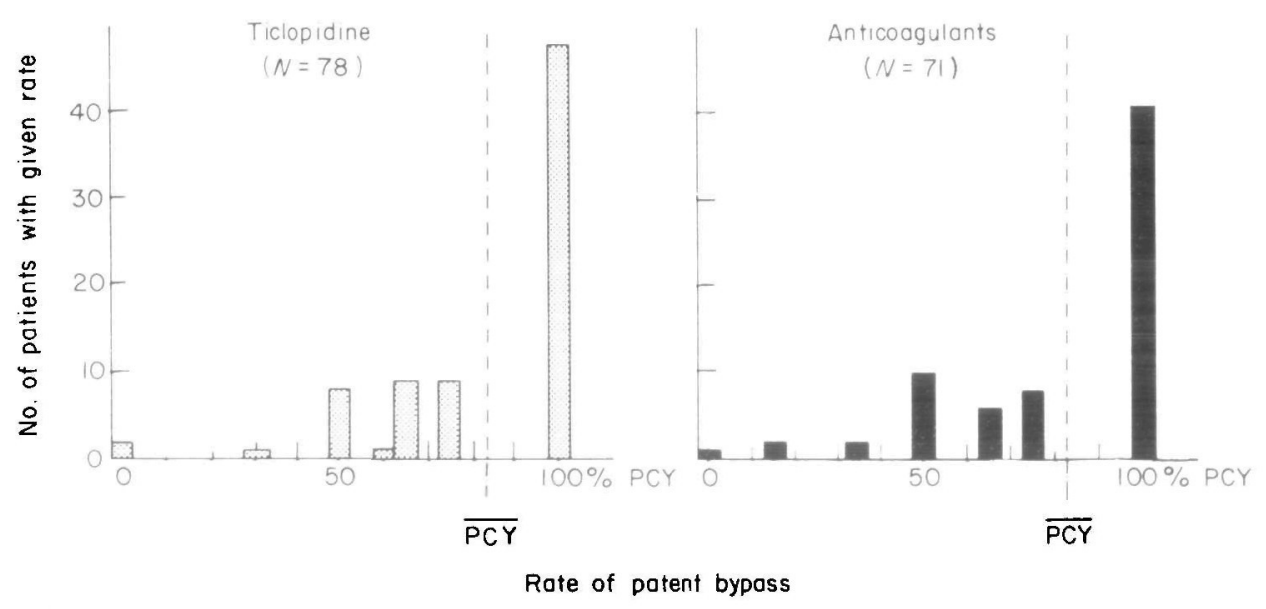

Figure I Histogram of individual patency rates (PCY) in patients with ticlopidine (average $\mathrm{PCY}=84 \cdot 2 \%$ ) or acenocoumarol (average $\mathrm{PCY}=81.6 \%$ ).

operation. On the other hand this complication was the most common cause of postoperative morbidity in the Stanford series ${ }^{[23]}$ before heparin was instituted routinely after the immediate operative period. In previously reported clinical studies on the prevention of bypass graft occlusion, pulmonary embolism had been repeatedly observed $^{\{9,11.12\}}$. The risk of pulmonary embolism is an additional indication for prophylactic antithrombotic measures during the early postoperative period. In the previously reported studies on the effect of anticoagulants or platelet active drugs on bypass patency, this problem has not been discussed, however ${ }^{[19.12 .23]}$.

After administration of either drug from the first to third postoperative day until angiography three months postoperatively, both treatment groups showed a very similar patency rate. This was the case for the total number of implanted bypass segments and for all segments anastomosed to the same individual coronary vessel. Since the patency of grafts from the same patient are not statistically independent variables, the individual graft segments were not used as observation units when performing statistical tests. The average patency rate per patient and the average rate of obstruction free bypass per patient were therefore preferred for statistical analysis. None of these variables revealed a significant difference in graft patency of patients receiving ticlopidine or acenocoumarol 


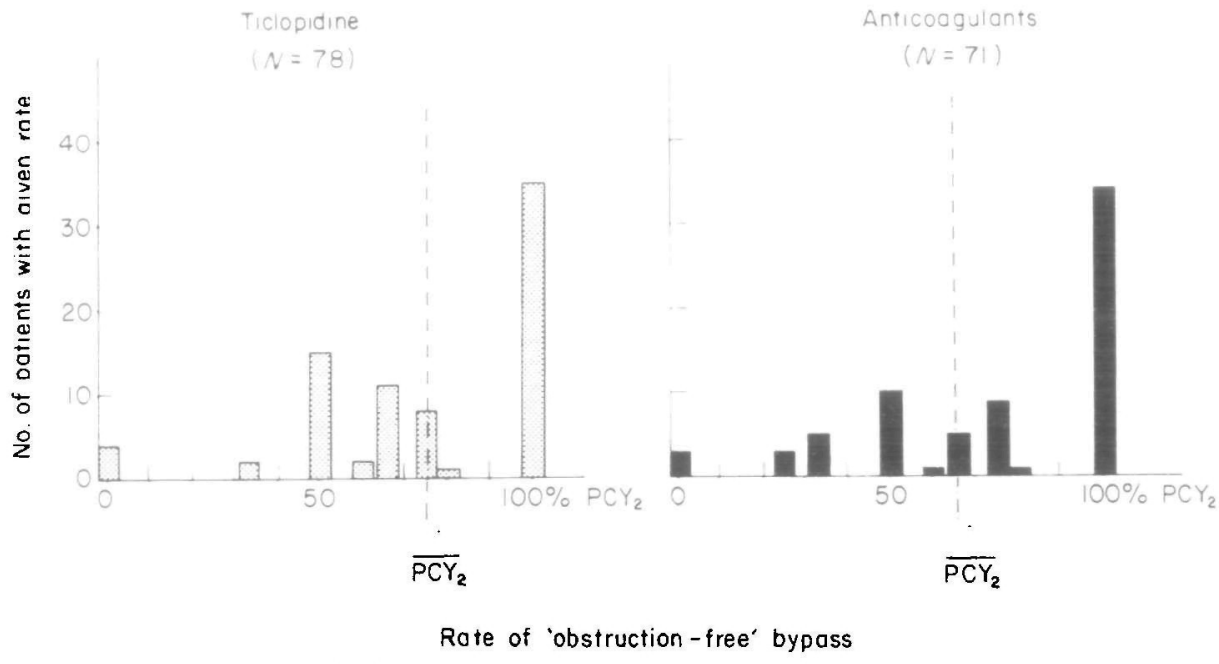

Figure 2 Histogram of individual 'obstruction free' rates $\left(\mathrm{PCY}_{2}\right)$, indicating less than $75 \%$ obstruction, in patients treated with ticlopidine (average $\mathrm{PCY}_{2}=75.0 \%$ ) or acenocoumarol (average $\mathrm{PCY}_{2}=74 \cdot 5 \%$ ).

Table 5 Variables entering a regression characterizing patients before entering into study

\begin{tabular}{lcccc}
\hline \multirow{2}{*}{ Independent variable } & \multicolumn{2}{c}{ PCY } & \multicolumn{2}{c}{$\mathrm{PCY}_{2}$} \\
\cline { 2 - 5 } & Coeff & $F$ & Coeff & $F$ \\
\hline Perioperative infarction & -0.303 & 14.8 & - & - \\
Third posterolateral branch & & & & \\
anastomosis & -0.370 & 5.3 & - & - \\
Medication* & -0.0003 & 0.0 & 0.014 & 0.09 \\
Constant & 0.687 & & 0.745 & \\
$R^{2}$ & 0.16 & & 0.0 & \\
Confidence interval & -0.074 & -+0.075 & -0.078 & -+0.105 \\
\hline
\end{tabular}

*Medication was forced of enter the regression.

(Figs I and 2). There were also no significant difference in the patient number with all grafts patent or with all grafts occluded in the two treatment groups. The calculated $95 \%$ confidence interval of graft patency indicates that the difference between the two types of treatment may vary between a reduction of graft occlusion by $7 \%$ and an enhancement of graft occlusion by $7 \%$. The corresponding values for rate of obstruction free grafts varied from a reduction of graft obstruction by $8 \%$ to an enhancement of graft obstruction by $10 \%$. Therefore for practical purposes it can be said from these observations, that there is no dif- ference with regard to patency rate between the two types of treatment.

Progression of stenotic lesions in native coronary arteries of the two treatment groups has been studied and reported separately ${ }^{[25]}$. Progression of obstruction was significantly more frequent in vessels with a bypass, particularly in lesions located proximal to a bypass anastomosis. Stenosis at the site of anastomosis itself was more common, if the bypass graft was occluded. Regarding the postoperative antithrombotic regimen no substantial difference in progression of stenotic lesions in native vessels was observed between 
patients receiving ticlopidine and those receiving acenocoumarol.

A drawback of the present clinical trial is the lack of a placebo group. After the report of a significant benefit of anticoagulants ${ }^{[10]}$ regarding patency of bypass grafts, the inclusion of a control group receiving no antithrombotic treatment was not acceptable to all participants of this trial. Direct proof that ticlopidine has beneficial effect on bypass graft patency can therefore not be derived from our data. Chevigné et al. ${ }^{[24]}$ have studied ticlopidine in a blinded trial after bypass surgery and very recently reported it to be an effective means to protect bypass patency in a subgroup of their randomized patients, who showed compliance to the treatment and who were restudied in time according to their protocol. Indirect evidence of an inhibitory effect of ticlopidine on bypass occlusion can also be derived from the present observations, since this drug was found to be as active as oral anticoagulants, which showed a significant beneficial effect on bypass patency in a previous trial ${ }^{[8]}$. A beneficial effect of oral anticoagulation had previously been postulated by McEnany et $a l^{[12]}$, while Pantely et al. ${ }^{[9]}$ could not find a significant difference in their very small series.

Preoperative administration of a platelet active agent would be most desirable, because platelet deposition occurs within seconds after implantation of a graft into the blood stream ${ }^{[19]}$ and can be influenced by preoperative administration of ticlopidine in animal experiments ${ }^{[19]}$. In our previously reported trial ${ }^{[20]}$, preoperative administration of ticlopidine significantly enhanced postoperative blood loss and the rate of reexplorations for bleeding. Although in other clinical studies no statistically significant difference in bleeding had been reported in cardiac surgery ${ }^{[26,27]}$ or after prostatectomy ${ }^{[2]}$, we concluded that preoperative routine administration of ticlopidine is not justified. In the limited experience with preoperative administration of ticlopidine there was no beneficial effect on patency rate ${ }^{[20]}$; however, the incidence of perioperative infarctions was significantly reduced $^{[21]}$. In this regard it is of interest, that aspirin, which prolongs bleeding time like ticlopidine, has been reported to increase the risk of postoperative bleeding [29]. This drug was withheld before surgery in clinical trials on prevention of bypass graft occlusion ${ }^{[9.11-14.16]}$, even in the study of Chesebro ${ }^{[13]}$, where the importance of preoperative start of medication was emphasized.

\section{Conclusions}

Interference with the pathways of thrombus formation in order to prevent thrombotic occlusion of aorto-coronary bypass is a two-edged venture. The treatment should be started before graft implantation for optimal effect, but the risk of operative and postoperative bleeding is against this. Moreover, pericardial effusion occurs frequently within the first two weeks after cardiac surgery and in association with anticoagulation cardiac tamponade may develop ${ }^{(30,31)}$. Finally the protective effect regarding venous thrombosis and pulmonary embolism should be considered. Aspirin, alone or in association to dipyridamole $e^{[6.11-13.16 .17]}$, sulfinpyrazone $e^{[14]}$ and oral anticoagulants ${ }^{[10]}$ have all shown favourable results in some trials, but no benefit in others ${ }^{[9,15]}$. Ticlopidine has been shown to be effective in one study ${ }^{(25)}$. In combination with oral anticoagulation it had no additional effect as compared with anticoagulation alone regarding patency rate. ${ }^{[20]}$. The present data indicate, that ticlopidine is as effective as oral anticoagulants if administered postoperatively. Side-effects were less common with ticlopidine than with anticoagulants and patient management was easier with a standard dosage of ticlopidine as compared with the individual adjustment of acenocoumarol to prothrombin time. If there is no increased risk for venous thrombosis and pulmonary embolism, ticlopidine may well be used instead of anticoagulants for the prevention of aorto-coronary bypass occlusion.

This study was supported by the Swiss Foundation for Cardiology. We thank Sanofi Pharma AG, Basel, Switzerland for providing ticlopidine. Statistical analysis was performed by $\mathrm{Dr} W$. Stahel and aggregation measurements were performed by $\operatorname{Dr} A$. von Felten, whose contributions are gratefully acknowledged.

\section{References}

[1] Lawrie GM. Lie JT, Morris GC, Beazley HL. Vein graft patency and intimal proliferation after aortocoronary bypass: early and longterm angiographic correlations. Am J Cardiol 1976; 38: 856-62.

[2] Sheldon WC, Rincon G, Effler DB. Proudfitt WL, Sones FM. Vein graft surgery for coronary artery disease. Circulation 1973; 48 (Suppl III): 184-9.

[3] Vlodaver Z, Edwards JE. Pathologic changes in aortocoronary and saphenous vein grafts. Circulation 1971; 44: 719-28.

[4] Bourassa MC, Lespérence J, Campeau L, Simard P. Factors influencing patency of aortocoronary vein grafts. Circulation 1972; 45 (Suppl I): 179-85. 
[5] Bulkley BH, Hutchins GM. Accelerated atherosclerosis" a morphologic study of 97 saphenous vein coronary artery bypass grafts. Circulation 1977; 55: 163-9.

[6] Chesebro JH, Fuster V, Elveback LR et al. Effect of dipyridamole and aspirin on late vein-graft patency after coronary bypass operations. N Engl J Med 1984; 310: 209-14.

[7] Fuster V, Dewanjee MK, Kaye MP et al. Noninvasive radioisotopic technique for detection of platelet deposition in coronary artery bypass grafts in dogs and its reduction with platelet inhibitors. Circulation 1979; 60: 1508-12.

[8] Josa M, Bianco RL, Kaye MP. Reduction of thrombosis in canine coronary bypass vein grafts with dipyridamole and aspirin. Am J Cardiol 1981; 47: 1248-54.

[9] Pantely GA, Goodnight SH, Rahimtoola SH et al. Failure of antiplatelet and anticoagulant therapy to improve patency of grafts after coronary artery bypass. N Engl J Med 1979; 301: 962-6.

[10] Gohlke H, Gohlke-Bärwolf $\mathrm{CH}$, Stürzenhofecker P. et al. Improved graft patency with anticoagulant therapy after aorto-coronary bypass surgery: A prospective randomized study. Circulation 1981; 64 (Suppl II): 22-7.

[11] Mayer JE, Lindsay WJ, Castaneda W, Nicoloff DM. Influence of aspirin and dipyridamole on patency of coronary artery bypass grafts. Ann Thorac Surg 1981; 31: 204-10.

[2I] McEnany MT, Salzman EW, Mundt ED et al. The effect of antithrombotic therapy on patency rates of saphenous vein coronary artery bypass grafts. J Thorac Cardiovasc Surg 1982; 83: 81-9.

[13] Chesebro JH, Clements IP, Fuster V et al. A platelet inhibitor drug trial in coronary artery bypass operations. N Engl J Med 1982; 307: 73-8.

[14] Baur HR, Van Tassel AR, Pierach CA, Gobel FL. Effects of sulfinpyrazone on early graft closure rate after myocardial revascularization. Am J Cardiol 1982; 49: 420-4.

[15] Sharma GVRK, Khuri SF, Folland ED et al. Lack of benefit from aspirin-dipyridamole therapy in aortocoronary vein graft patency. Circulation 1982; 66 (Suppl II); II-94 (Abstr).

[16] Lorenz RL, Weber M, Kotzur J et al. Improved aortocoronary bypass patency by low dose aspirin. Lancet 1984; i: 969-71.

[17] Brown BG, Cukingnan RA, Goede L et al. Improved graft patency with antiplatelet drugs in patients treated for one year following coronary bypass surgery. Am J Cardiol 1981; 47: 494 (A bstr).

[18] Panac E, Maffrand JP, Picard-Fraire C et al. Ticlopidine: a promise for the prevention and treatment of thrombosis and its complications. Haemostasis 1983; 13 (Suppl I): I-54.
[19] Walter P, Geroulanos $\mathrm{S}$, Rothlin $\mathrm{M}$ et al. Die rasterelektronenoptischen Oberflächenveränderungen der Gefässinnenfläche gewobener Dacrongefässprothesen nach Verabreichung von Ticlopidine. Folia Angiol 1981; 29: 20-32.

[20] Rothlin ME, Pfluger N, Speiser $\mathrm{K}$ et al. Clinical experience with antiplatelet drugs in aorto-coronary bypass surgery. In: Bruschke AVG, van Herpen $G$, Vermeulen FEE, eds. Coronary artery surgery today. Excerpta Medica, International Congress Series 1982; 557: 413-9.

[21] Pfluger N, Speiser K, Goebel N, Rothlin ME. Die Bedeutung des thrombotischen Gefässverschlusses für den perioperativen Infarkt in der Koronarchirurgie. In preparation.

[22] Thébault JJ, Blatrix CE, Blanchard JF, Panac EA. Effects of ticlopidine, a new platelet aggregation inhibitor in man. Clin Pharmacol Ther 1975; 18: 485-90.

[23] Griffin JC, Valdez R, Harrison DC. Long term follow up of patients undergoing aortocoronary bypass grafting. In: Yu PN, Goodwin JF, eds. Progress in cardiology Ed. P. N. Yu and J. F. Goodwin; Lea and Febiger Philadelphia $1977 ; 6: 137-63$.

[24] Chevigné $M$, David JL, Rigo P, Limet R. Effect of ticlopidine, on saphenous vein bypass patency rates: $A$ double blind study. Ann Thorac Surg 1984; 37: 371-8.

[25] Goebel N, Pfluger N, Speiser K et al. Veränderungen in den Nativgefässen nach aorto-koronarer Bypassoperation. Fortschr Röntgenstr 1983; 139: 595-602.

[26] Renner C, Guilmet D, Curtet JM. La ticlopidine en chirurgie cardiaque avec circulation extracorporelle. Nouv Presse Méd 1980; 9: 3249-51.

[27] Installe E, Gonzalez M, Schoevaerdts JC, Trémouroux J. Prevention by ticlopidine of platelet consumption during extracorporeal circulation for heart surgery and lack of effect on operative and postoperative bleeding. $J$ Cardiovasc Pharmacol 1981; 3: 1174-83.

[28] Brommer EJP. The effect of ticlopidine upon platelet function, hemorrhage and postoperative thrombosis in patients undergoing suprapubic prostatectomy. J Int Med Res 1981; 9: 203-10.

[29] Torosian M, Michelson EL, Morganroth J, MacVaugh H. Aspirin- and coumadin-related bleeding after coronary artery bypass graft surgery. Ann Int Med 1978; 89: 325-8.

[30] Hochberg MS, Merrill WH, Gruber M, McIntosh CL et al. Delayed cardiac tamponade associated with prophylactic anticoagulation in patients undergoing bypass grafting: early diagnosis with two dimensional echocardiography. J Thorac Cardiovasc Surg 1978; 75: 777-83.

[31 Borklon JL, Schaff HV, Gardner TJ et al. Diagnosis and management of postoperative pericardial effusion and late cardial tamponade following open heart surgery. Ann Thorac Surg 1981; 31: 512-8. 